\title{
Inventory Management and Maintenance in Offshore Vessel Industry
}

\author{
Jalel Ben Hmida, Grant Regan, and Jim Lee \\ Systems Engineering, University of Louisiana at Lafayette, Room 244 CLR Hall, P.O. Box 44170, Lafayette, LA 70504-2250, USA \\ Correspondence should be addressed to Jalel Ben Hmida; jxb9360@louisiana.edu
}

Received 19 November 2012; Revised 22 February 2013; Accepted 22 February 2013

Academic Editor: Anis Chelbi

Copyright (C) 2013 Jalel Ben Hmida et al. This is an open access article distributed under the Creative Commons Attribution License, which permits unrestricted use, distribution, and reproduction in any medium, provided the original work is properly cited.

\begin{abstract}
An evaluation of the inventory policy at an offshore vessel company was conducted. Currently the items in inventory are used at random intervals as they are used only when parts fail. To solve the problem of reducing a very large inventory but keep enough to allow an uninterrupted service to the customer, we propose a real and economically efficient multicriteria inventory policy using inventory classification method integrated with a preventive maintenance program. The proposed method can be summarized in the following three steps: first, rank the parts according to both the lead time from supplier and the cost of downtime failure and use a matrix display to show the most critical items. In the second step develop a preventive maintenance program for the most critical parts to minimize downtime due to failure. Finally in the third step standardize most critical parts to reduce the inventory which saves the company money while maintaining the same level of service to its customers. Our study showed that the company with a very large inventory could effectively reduce its size by focusing on key parts.
\end{abstract}

\section{Introduction}

Due to the increasing pressure for remaining competitive in the global market place, inventory management has become a major challenge for companies to reduce costs and to improve customer service.

Most manufacturing and service companies large or small have some type of inventory. The items in inventory are there to make the day-to-day operations of the company more efficient and the flow of goods smoother. While too much inventory reduces capital that can be directed into other aspects of the company's operations, not enough causes other serious problems such as loss of sales and customer dissatisfaction. The challenge then becomes to effectively coordinate the overall inventory so the optimal amounts are maintained [1].

While working with an offshore vessel company, we have witnessed the problems regarding inventory first hand. The company provides service to oil and gas companies in the Gulf of Mexico. They lease a vessel from the company for a predetermined price set by the job the vessel will perform while under contract. If the vessel is not maintained correctly and breaks, then it becomes unusable. The unusable time becomes a downtime for the vessel, resulting in a loss of revenue.

At times parts are hard to find because the vessels work from off the coast of Alabama to the southern coast of Texas, especially in an emergency situation where the vessel is in need to be repaired and returned to work right away. Therefore, there is an abundance of spare parts in inventory. Also, because the oil and gas industry operates twenty-four hours a day seven days a week, the parts need to be available to the mechanics at all times. The revenue generated per day is very high and the loss due to downtime is unrecoverable, so when a vessel breaks it becomes the goal of the manager to do whatever it takes to return the vessel back to work. In doing so in this stressful situation, the inventory cost is nearly always overlooked. Customer satisfaction is the main goal, and having a fully functional vessel becomes the top priority. This insures current revenue and a satisfied customer guaranteeing future revenue.

To avoid a downtime in the future, when a part is replaced an extra part is bought and put into inventory for the next time it happens to break to avoid the chances of a downtime. 
With over two hundred employees and more than thirty vessels, the company carries a large inventory of spare parts evaluated to be worth over 3.5 million dollars without any formal inventory management policy.

The primary objective of this case study is to propose a real and economically efficient inventory policy for this offshore vessel company. Currently the items in inventory are used at random intervals as they are used only when parts fail. To solve the problem of reducing a very large inventory but keep enough to allow an uninterrupted service to the customer, we propose an inventory policy using inventory classification method with a preventive maintenance program.

Our first step is to rank the parts in the inventory. This ranking system will not be one dimensional but rather two dimensional factoring in the expected lead time to receive an item and the cost of downtime that would result in not having the item in inventory. A matrix is used to show the relative importance of the items which allows managers to identify critical items. In the next step we propose the use of a preventive maintenance program to estimate the frequency a critical item may be needed. Finally we suggest the standardization of parts to reduce the inventory. Taking the three steps and applying them together into an inventory policy has created a more predictable environment which saves the company money in inventory while maintaining the same level of service to its customers.

\section{Literature Review}

The ultimate goal of managing inventory is to satisfy the demand level at minimum cost [2]. The Just-in-Time (JIT) method is an inventory strategy companies employ to decrease waste by receiving goods or producing goods at the right time to meet the demands of the production process and the demands of the company's end customers [3]. Ultimately, this translates into saving the company money, but JIT is not always the best method available to a specific company. When a company's operation is not time based, the production and the demand of a product cannot be predicted [4].

A similar method closely related to Just-in-Time is the Materials Requirement Planning (MRP) method which is a prominent approach to managing the flow of raw material and components on the factory floor [5]. The advantages to this system just as in JIT is to reduce the inventory to a minimum. However, it was backward looking, assuming that future demand for an inventory was predictable and mirrors the past. The challenge with MRP, much the same as JIT, is to determine the optimal time to request materials ahead of requirements. In an unpredictable time based environment the future demand can not be calculated resulting in excessive inventory and obsolete stock.

To evaluate inventory some firms use a classification system known as the $\mathrm{ABC}$ method. This method classifies items based on their cost or the frequency they are used. One weakness of $A B C$ classification is that there is not a definite method to assign products to appropriate categories. Similarly there is no objective way to determine the correct number of categories to use. Although a product may be a slow mover and therefore classified as a " $\mathrm{C}$ " item, it may have a high profit margin. Also carrying " $\mathrm{C}$ " items may be necessary to maintain existing customers and attract new ones. To deal with this situation, a multiple-criteria $A B C$ classification has been suggested $[6,7] . A B C$ is integrated with a mixed integer program (MIP) in Kirche \& Srivastava [8] for order management. Bhattachaya et al. [9] developed a procedure based on $\mathrm{ABC}$ and perishability of items. Hincapie [10] developed a decision support system which ranks component parts by integrating multi-criteria classification methods. The decision is to manufacture the parts that have the highest priority.

In real world situation the frequency that a part is used may be unpredictable. Also, it is very costly to have unused machines caused by part failure. The cost of not having a part to repair a machine is much greater than both the holding cost plus the cost of the item [11]. In this situation, parts are kept in inventory to repair the machines that the company uses to offer their services to the customers. The frequency a part is used can be controlled by scheduling it to be replaced before it fails. This can be done through a regularly scheduled preventive maintenance [12]. A preventive maintenance program consists of preventive measures, which are the basic elements of maintaining equipment and the first line of defense in building a sound maintenance program [13]. Chelbi et al. [14] proposed and modeled an inspection and preventive maintenance policy for randomly failing systems.

Rezg et al. [15] investigated an integrated strategy of inventory control and preventive maintenance for a randomly failing production unit subject to a minimum required availability level. The production unit is submitted to a maintenance action as soon as it reaches a certain age $\mathrm{m}$ or at failure. A buffer stock $\mathrm{h}$ is built up at time $\mathrm{A}$ from the start of a production cycle in order to allow a continuous supply of the subsequent production unit at a constant rate during repair and preventive maintenance actions whose respective durations are random. Duarte et al. [16] presented a model and algorithm for maintenance optimization of a system with series components. They assumed that all components have linearly increasing failure rate with a constant improvement factor for imperfect maintenance. In addition, they considered the total cost as the objective function and the total downtime as the main constraint. In terms of maintenance activities, they defined preventive and corrective maintenance for each component.

There are misconceptions about preventive maintenance. One such misconception is that preventive maintenance is an unneeded extra cost. This misconception dictates that it would cost more for regularly scheduled maintenance than it would cost to operate the equipment until repair is absolutely needed. To justify the cost savings associated with an effective preventive maintenance one needs to look at the benefits and savings in the long-term avoiding unscheduled equipment breakdown. It is a logical choice if the following conditions are met: (1) the component in question has an increasing failure rate, and (2) the overall costs of the preventive maintenance action must be less than the overall cost of a corrective action [17]. 
In recent years there has been an increase in the use of proactive maintenance techniques for repair and maintenance of machinery $[18,19]$. Oil analysis to monitor the equipment condition in determining when to perform maintenance is an example of predictive measure. As more predictive measures are identified as having economic benefit in maintaining the company's assets, those measures can be implemented accordingly. Furthermore, there have been numerous advances in condition monitoring technology, trending, and increasingly more powerful planned maintenance software. In an unpredictable time based environment using a scheduled preventive maintenance program with a classification method creates a predictable inventory situation. Therefore using a combination of the previously mentioned methods of inventory will solve the inventory problem both reducing the inventory and saving costs.

\section{Case Study}

The goal of the company in our case study is to supply its customers who lease their vessels with an optimal level of service. Because the company is one of service and not manufacturing, the reliability on its spare parts in inventory is crucial. The inventory of parts is needed to provide emergency services in returning their vessels back to work in the shortest amount of time possible. Over the years, the company has accumulated a large inventory with no formal procedure to manage it, allocating unnecessary funds that could be used elsewhere in the company. An inventory policy needs to be created to assist in this task.

3.1. Downtime Cost and Lead Time Estimation. Having a vessel shut down for any reason, whether it is for inspection, maintenance, or malfunction, costs the company money for every moment it is out of commission. Knowing the precise cost can help managers make decisions as to when to downtime a vessel, or in the case of repairs, how much to spend on getting the vessel running again. In order to accurately project the costs, we will have to know what is being affected by the downtime. While idled labor and lower productivity costs may seem to be the most substantial cost of downtime, any true cost of downtime estimate should include the value of the opportunities that were lost when the applications were not available.

To calculate the total downtime cost we need to add the following costs.

(i) Labor cost, both direct and indirect, of the downtime. To find the direct labor costs, take the length of the downtime and multiply it by the hourly rate of the vessel operators. Calculate indirect labor costs by determining how much of a share of the supervisory and support workload the vessel takes, then multiplying that by the costs of the support staff and managers.

(ii) The cost of direct value loss due to the downtime. The loss is equal to the worth of the service that would have been produced during the downtime.
TABLE 1: Inventory data.

\begin{tabular}{lcccc}
\hline Part & Cost (new) & $\begin{array}{c}\text { Cost } \\
\text { (repair) }\end{array}$ & Availability & $\begin{array}{c}\text { Downtime } \\
\text { cost }\end{array}$ \\
\hline Ballast pump & $\$ 1400$ & $\$ 500$ & 7 & $\$ 16,387$ \\
Starter & $\$ 900$ & $\$ 200$ & 6 & $\$ 15,000$ \\
Mud pump & $\$ 2000$ & $\$ 700$ & 5 & $\$ 10,925$ \\
Filter & $\$ 30$ & $\$ 30$ & 1 & $\$ 2,185$ \\
Valves & $\$ 100$ & $\$ 30$ & 3 & $\$ 5,462$ \\
\hline
\end{tabular}

(iii) The start-up costs related to restarting the vessel, including any additional workers needed, energy surges, and inspection costs.

(iv) The costs related to repair of the part, either temporarily or permanently.

Because the cost of downtime will almost always exceed the cost of the part, all items are equally valuable to the operations of the company. To distinguish items of interest from other items, additional data needs to be collected rather than just the price of the parts.

The data needed is the lead time of the part and the cost of downtime, rather than just the price of a new part. Because the price of new parts in inventory is less than the cost it would incur while not having it, the cost of downtime is used, instead, along with the lead time associated with that item. For example, a generator costs $\$ 15,000$ brand new and the generator is critical to the operations; if it became broken it would incur a large downtime cost of $\$ 25,000$. The cost of downtime is calculated using the procedure explained above.

In some cases it may be possible to offer some services but not others, for example having a pump not working that would transfer cargo from tanks below the deck of the vessel to a rig in the Gulf. The vessel is still capable of carrying cargo above the deck to and from the rig and is still operational in that manner therefore it may be classified as $50 \%$ operational. This would calculate to a downtime costing $50 \%$ of the usual cost. The items of interest are those which are hard to receive in a short period of time and cause an expensive downtime loss to the company. It takes some items weeks to receive while others are readily available at any time. The lead time of the items are to be ranked on a scale of one to ten, ten having a long lead time and one being readily available. After the entire inventory data is collected and recorded into a spreadsheet, a sample data is shown in Table 1.

3.2. Multiattribute Inventory Classification. After the downtime cost and lead time are determined, the data should be plotted onto a graph resulting in a matrix to show a visual representation of the items in inventory. This will give the managers a visual tool to use to easily identify items of interest and help in making a decision on which items to keep in inventory.

The goal is to minimize the losses by providing a ranking method similar to the $A B C$ classification. Using the $A B C$ classification approach justifies having all items in inventory while not solving the real problem which is reducing the 
inventory. To better visualize how critical a part is, the data of the items in inventory need to be plotted onto a graph resulting in a matrix allowing a manager to visually see which items are of interest and would then be inventoried.

The graph will plot the cost of downtime along the " $X$ " axis starting at zero to the cost of a complete loss due to downtime. The lead time of the item will plot along the " $Y$ " axis on a scale of one to ten. Items with a low cost of downtime and are readily available will plot in the lower left hand corner. Items of low availability and that cause an expensive loss in downtime will plot in the upper right hand corner. Using the sample data from Table 1, a plot is produced in Figure 1. Based on budget constraints the manager can adjust the graph and easily decide which items to inventory.

As displayed in Figure 1, a ballast pump is a part that needs to be inventoried. Evaluation of this part will show how these policies will succeed in reducing the inventory and save money when applied to all parts throughout the inventory.

The ballast pump is critical to the operations of a vessel. Its duties include taking water onboard the vessel, pumping water from the vessel to a rig, and also transferring water from one tank to another to level off the vessel. A brand new pump costs about $\$ 1400$, and about $\$ 500$ to repair. It is available from various vendors, but having the right pump, with the correct specifications, can be difficult to find sometimes. Therefore, the lead time is ranked as seven. The downtime cost was determined by adding all costs involved when the pump is out of use. When a vessel takes on cargo, water may need to be shifted from one tank to another to avoid an unbalanced vessel; not doing so could potentially be hazardous causing the vessel to roll over and sink. The vessel has two pumps and therefore can operate with only one for a short time, but because it still needs both it scored high for the downtime cost.

When plotted onto a graph the pump would fall into the upper right-hand corner indicating it is rather hard to find and causes a high cost for downtime. A manager can easily see that the pump is needed and needs to have one in inventory to replace a broken one, should an emergency arise.

3.3. Preventive Maintenance Program Development. After knowing what parts are critical, the survival of those parts will save the company money. In recent years there has been an increase in techniques for repair and maintenance of machinery to prolong the life of parts. Preventive maintenance consists of procedures to extend the life of a part using proactive measures to prevent a part from breaking prematurely. Preventive maintenance also includes practices where a part is changed before it is scheduled to break, so the frequency items will be needed and how many of each item will need to be inventoried can be determined.

Machines in a manufacturing facility do not operate $100 \%$ of the time in most cases. During the time that which a machine is idle, preventive maintenance measures can be conducted and parts that are soon scheduled to fail can be changed, resulting in higher productivity because of the reduced chances of downtime due to a part failure. The part can in some cases then be repaired, as it is cheaper to repair a part, if possible, rather than purchasing a complete new

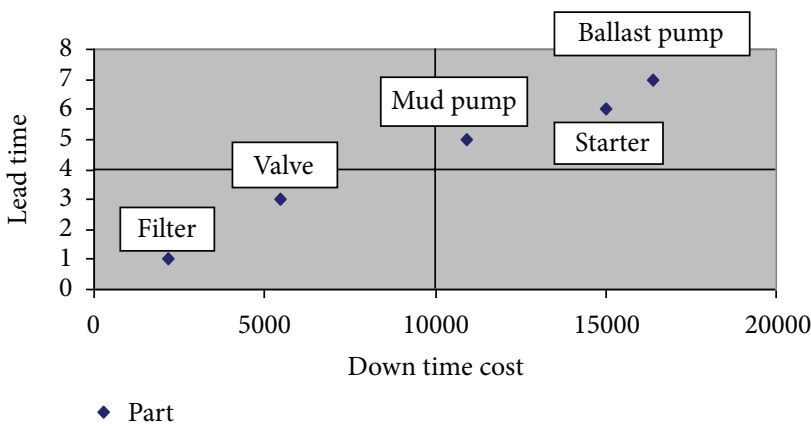

FIGURE 1: Inventory classification.

part. If the preventive maintenance program is scheduled correctly, parts can be changed before they become beyond repair. As parts are changed data can be used to improve the maintenance further prolonging the life of the part and also a better predictability of the mean time between failures.

In our case study, some simple procedures can prolong the life of the pump and changing it before it fails will greatly reduce the chances of causing a period of downtime. Procedures from the manufacturer's manual are summarized in the Table 2. The basic cost of preventive maintenance is cheap. The only cost that would incur is the cost of time, in the form of labor, and materials, such as grease, when inspecting the functionality of the pump during the weekly, monthly, and semiannual tasks. The cost of a new pump is $\$ 1400$ and the cost to repair it is about $\$ 500$. The ballast pump currently fails and needs to be replaced about once every fourteen months. The repair cost is much cheaper than to replace it so the decision to change it at one year, regardless if the pump is not broken, is part of the maintenance schedule.

Also taking the pump off the vessel and replacing it with another one eliminates the failure of that pump for another year reducing the chances of loss due to downtime cost. Since the day-rate for a vessel over 200 ' is $\$ 21,050$, the company saved a potential loss of business plus the cost of a new pump for a total of about $\$ 21,850$. Previously, pumps usually failed between 12 and 14 months. It was decided to change the pumps at its earliest mean time between failure rate at 12 months to both prevent it from breaking and causing a lost of production and also to change it before it becomes beyond repair. As the pump is being repaired notes can be taken on how to better maintain it.

3.4. Parts Standardization. The policy to implement the preventive maintenance should also be combined with a policy to standardize the parts. There are many similar parts in inventory that can be grouped. We looked at the different pumps in the inventory. The only difference in each of them is a small modification such as impeller size or the inlet and outlet sizes or the base of the pump. All these parts of the pumps can be changed to make the pump meet the specifications needed for a particular job. The impeller can be changed or the housing can also be changed with a different inlet and outlet size. Doing so can allow the elimination of the various pumps and replacement with one or two pumps 
TABLE 2: Ballast pump preventive maintenance procedures.

\begin{tabular}{|c|c|c|}
\hline Weekly & $\begin{array}{l}\text { (i) Visually inspect pump for leaks } \\
\text { (ii) Clean exterior surface of pump/motor } \\
\text { (iii) Check level of the oil in bearing cavity } \\
\text { (iv) Ensure instruments (gauges) and controls are in good working order }\end{array}$ & $\begin{array}{l}\text { Cost: } \$ 0-10 \\
\quad \text { (labor) }\end{array}$ \\
\hline Monthly & $\begin{array}{l}\text { (i) Run pump for } 30 \text { min minimum } \\
\text { (ii) Note and record the following } \\
\text { (a) Pump suction and discharge pressure } \\
\text { (b) Frequency voltage } \\
\text { (c) Amperage } \\
\text { (iii) Check foundations on pump, tighten all loose bolts as needed }\end{array}$ & $\begin{array}{l}\text { Cost: } \$ 0-10 \\
\quad \text { (labor) }\end{array}$ \\
\hline Simi-Annually & $\begin{array}{l}\text { (i) Secure power to unit, use lockout/tagout procedures } \\
\text { (ii) Adjust packing to allow for cooling and prevent excess leak-off as per } \\
\text { instructions of engineer } \\
\text { (iii) Lubricate packing as per manufacturer's specifications } \\
\text { (iv) Grease bearings per manufacturer's instructions } \\
\text { (v) Restore power to unit } \\
\text { (vi) Test run pump }\end{array}$ & $\begin{array}{l}\text { Cost: } \$ 50-80 \\
\text { (labor and materials) }\end{array}$ \\
\hline Annually & $\begin{array}{l}\text { (i) Replace pump with spare from warehouse } \\
\text { (ii) Send old pump to warehouse for repair }\end{array}$ & Cost: $\$ 500$ \\
\hline Total & & $\$ 600$ \\
\hline Cost of new pump & & $\$ 1400$ \\
\hline Savings & & $\$ 800$ \\
\hline
\end{tabular}

TABLE 3: Savings with standardization.

\begin{tabular}{lccc}
\hline Part & Cost of pump & Cost of parts & Total \\
\hline (5) Ballast pumps & $(5) \$ 1,400$ & $\$ 0$ & $\$ 7,000$ \\
(1) Ballast pump & $\$ 1,400$ & $(5) \$ 200$ & $\$ 2,400$ \\
\hline Savings & & & $\$ 4,600$ \\
\hline
\end{tabular}

along with spare parts of the pumps to modify a single pump to meet the correct specifications at a fraction of the cost. This generates more savings for the company as summarized in Table 3 .

Both the standardization of the pumps along with the preventive maintenance will save the company money as shown. Although the company will save $\$ 800$ for every pump it replaces before it fails and $\$ 4,600$ with the elimination of the erroneous pumps in inventory, the company saves greatly by having no loss of service offered to the customer in addition to reducing its inventory.

\section{Discussion}

Inventory is often seen as a "set and forget" asset, and once inventory levels have been optimized it is not needed to revisit again. In the real world, there is no one-size-fitsall maintenance strategy or approach. The inventory must remain flexible and the data must be continually updated. As parts are being used and standardized, parts will develop a trend for their use. This trend can be used to create an environment similar to JIT and MRP resulting in a minimal amount of parts in inventory.

As items are changed and repaired the frequency with which they are changed will provide useful data. This data will show the mean time between failures and will also allow the calculation of how many need to be inventoried. Using the data from the failed parts will also allow for better maintenance of the parts to exceed the manufactures expectations. To effectively calculate this, the manufacture's recommendations for the preventive maintenance of the parts should first be used. As parts are changed, the reason for failure needs to be recorded. This will provide information to improve the preventive maintenance of the part in order to extend the time between failures. Also the frequency a part is used needs to be recorded. This information along with the lead time of the part will effectively allow the calculation of how many parts need to be in inventory and how often they need to be ordered.

The result of knowing when a part will be needed to be changed creates a predictable demand for the part as needed in JIT and MRP inventory environments giving a manager a more accurate level of safety stock and reorder point. Before, parts were used as they were needed and the time they were needed was unknown and very random. After implementing preventive maintenance procedures the demand for a part becomes more predictable resulting in less downtime and more accurate inventory safety stock and reorder points.

In this research we developed a ranking system for the parts in the inventory of an offshore vessel company. This ranking system takes in consideration the expected lead time from supplier and the cost of downtime failure. A matrix was used to show the most critical items. In the next step we used a preventive maintenance program for the most critical parts to minimize downtime due to failure. Finally we did a standardization of the most critical parts to reduce the inventory. This multi-criteria inventory policy involving the three steps has created a more predictable environment 
which saves the company a lot of money in inventory while maintaining the same level of service to its customers.

We showed that this multi-criteria ranking system suits this company better than an $\mathrm{ABC}$ classification which is based on the cost of the different parts because there is not a definite method to assign products to appropriate categories in the $\mathrm{ABC}$ method. In the same context, the proposed inventory policy works much better for this company than traditional methods like Just-in-Time or Materials Requirement Planning because the objectives of JIT and MRP is to determine the optimal time to request materials ahead of requirements. In an unpredictable time based environment, like this offshore vessel company, the future demand cannot be calculated resulting in excessive inventory and obsolete stock.

For this company that operates more than thirty vessels, the number of downtime days for the year 2011 was 974 days. $8 \%$ of the failures are related to pumps, which means 78 downtime days. After application of the proposed inventory policy, the number of downtime days due to pumps failure for the first six months of the year 2012 was 22 days. The company will save 34 service days for the whole year which means a gain of 714 thousand dollars plus a reduction of $10 \%$ in inventory which saves an extra 350 thousand dollars.

\section{Conclusion}

Effective inventory management is a crucial function and plays a pivotal role in basic engineering management. When a company handles many products in their inventory and the demand is unpredictable the common approaches can not be used but rather need to be adapted to better fit the environment to assist the company in their inventory management. The solution developed concentrates on knowing what items are critical to inventory and to identify what items do not need to be inventoried. It also focuses on keeping the critical items in service through preventive maintenance and the standardization of parts to reduce the inventory. The proposed solution saved the company more than one million dollars in one year.

Further enhancements in this solution can be done by using more encompassing maintenance strategies such as imperfect maintenance or even conditional preventive maintenance methods. Using better preventive maintenance strategy will improve parts life and avoid any unplanned maintenance activity.

Another enhancement is the effectiveness of creating vendor and customer relationships to handle the parts that fall into the lower right hand corners of the matrix and upper left hand corner. These parts cause a great downtime cost but they have a small lead time or they cause a small cost in downtime but have a longer lead time and are not as critical to inventory. Because they are not as critical as items in the upper right hand corner of the matrix a relationship created with a vendor could include that he carry the items in inventory with the promise that parts would be purchased from him when they are needed. This makes the parts available with a smaller lead time and reduces the holding cost of carrying them in the company's inventory. Inventory management policies must be continuously revisited and improved upon to be effective.

\section{References}

[1] R. Ballou, Business Logistics Management, Prentice Hall, Englewood Cliffs, NJ, USA, 5th edition, 2003.

[2] T. Harris, "Optimized inventory management," Production and Inventory Management Journal, vol. 38, no. 1, pp. 22-25, 1997.

[3] H. H. Jordan, "Inventory management in the JIT age," Production and Inventory Management Journal, vol. 29, no. 3, pp. 57-60, 1988.

[4] L. Abuhilal, G. Rabadi, and A. Sousa-Poza, "Supply chain inventory control: a comparison among JIT, MRP, and MRP with information sharing using simulation," Engineering Management Journal, vol. 18, no. 2, pp. 51-57, 2006.

[5] V. A. Mabert, "The early road to material requirements planning," Journal of Operations Management, vol. 25, no. 2, pp. 346356, 2007.

[6] R. Ramanathan, "ABC inventory classification with multiplecriteria using weighted linear optimization," Computers and Operations Research, vol. 33, no. 3, pp. 695-700, 2006.

[7] A. Hadi-Vencheh, "An improvement to multiple criteria ABC inventory classification," European Journal of Operational Research, vol. 201, no. 3, pp. 962-965, 2010.

[8] E. Kirche and R. Srivastava, "An ABC-based cost model with inventory and order level costs: a comparison with TOC," International Journal of Production Research, vol. 43, no. 8, pp. 1685-1710, 2005.

[9] A. Bhattacharya, B. Sarkar, and S. K. Mukherjee, "Distancebased consensus method for ABC analysis," International Journal of Production Research, vol. 45, no. 15, pp. 3405-3420, 2007.

[10] J. Hincapie, J. Lee, and W. Emblom, "Sensitivity analysis on inventory classification methods for oilfield equipment industry," in Proceedings of the International Manufacturing Science and Engineering Conference, pp. 145-153, 2011.

[11] Y. L. Koçağa and A. Şen, "Spare parts inventory management with demand lead times and rationing," IIE Transactions, vol. 39, no. 9, pp. 879-898, 2007.

[12] T. S. Vaughan, "Failure replacement and preventive maintenance spare parts ordering policy," European Journal of Operational Research, vol. 161, no. 1, pp. 183-190, 2005.

[13] J. Morelli, "ABCs of rectifier maintenance. A carefully planned preventative upkeep program can reduce unscheduled downtime," Metal Finishing, vol. 107, no. 3, pp. 34-37, 2009.

[14] A. Chelbi, D. Ait-Kadi, and H. Aloui, "Optimal inspection and preventive maintenance policy for systems with selfannouncing and non-self-announcing failures," Journal of Quality in Maintenance Engineering, vol. 14, no. 1, pp. 34-45, 2008.

[15] N. Rezg, S. Dellagi, and A. Chelbi, "Joint optimal inventory control and preventive maintenance policy," International Journal of Production Research, vol. 46, no. 19, pp. 5349-5365, 2008.

[16] J. A. C. Duarte, J. C. T. A. Craveiro, and T. P. Trigo, "Optimization of the preventive maintenance plan of a series components system," International Journal of Pressure Vessels and Piping, vol. 83, no. 4, pp. 244-248, 2006.

[17] G. Toomey, "Harnessing the power of maintenance," Power Engineering, vol. 110, no. 3, pp. 42-47, 2006. 
[18] C. M. I. Da Silva, C. M. P. Cabrita, and J. C. De Oliveira Matias, "Proactive reliability maintenance: a case study concerning maintenance service costs," Journal of Quality in Maintenance Engineering, vol. 14, no. 4, pp. 343-355, 2008.

[19] M. Kans, "The advancement of maintenance information technology: a literature review," Journal of Quality in Maintenance Engineering, vol. 15, no. 1, pp. 5-16, 2009. 

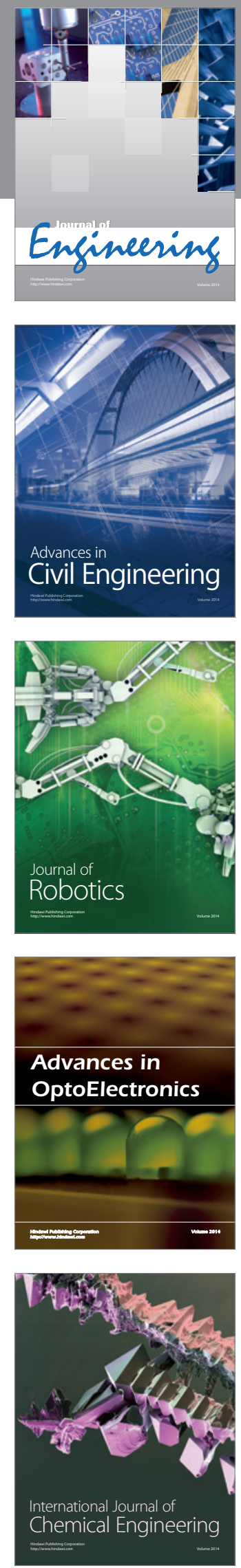

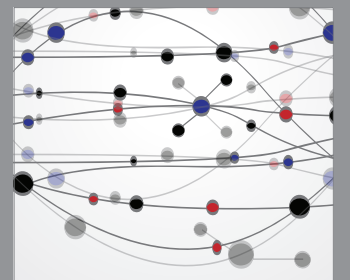

The Scientific World Journal
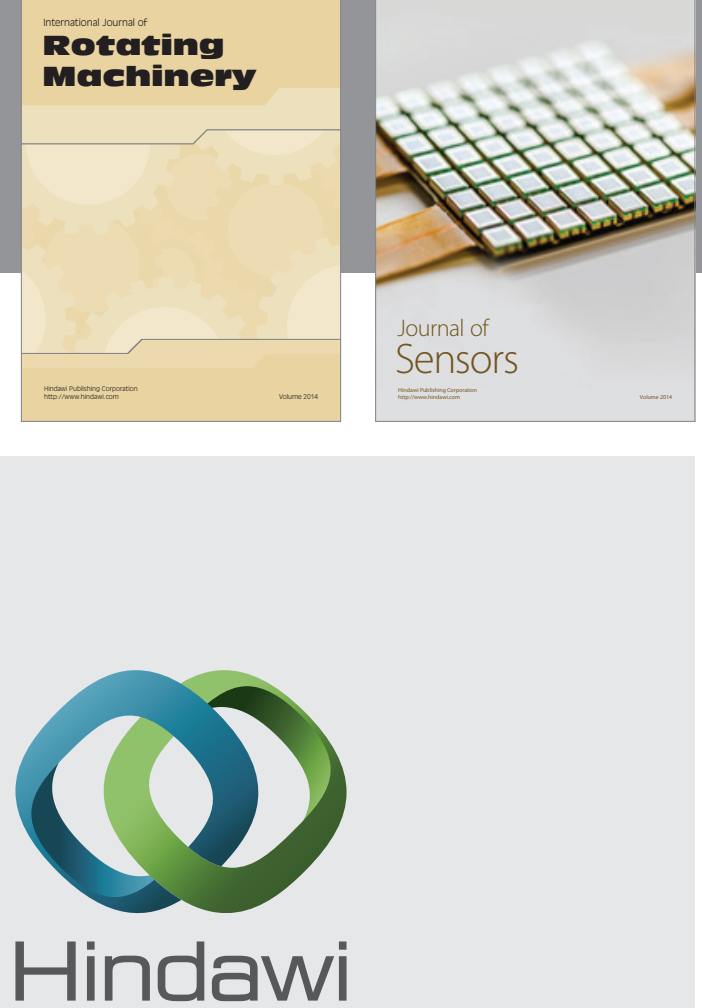

Submit your manuscripts at http://www.hindawi.com
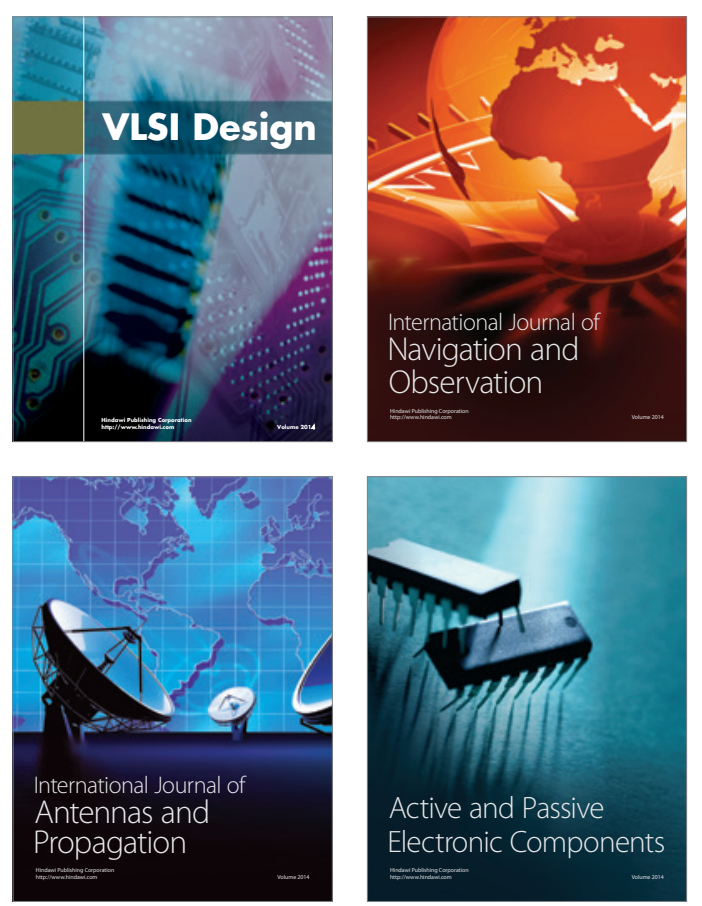
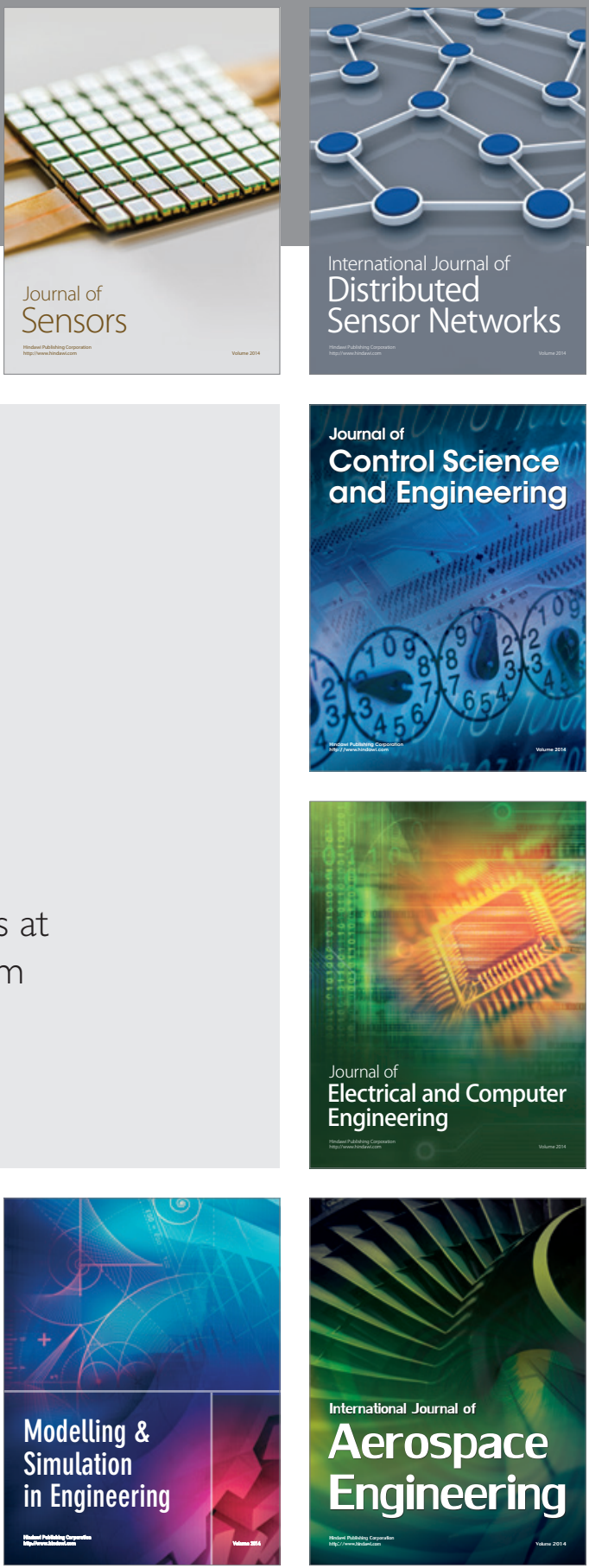

Journal of

Control Science

and Engineering
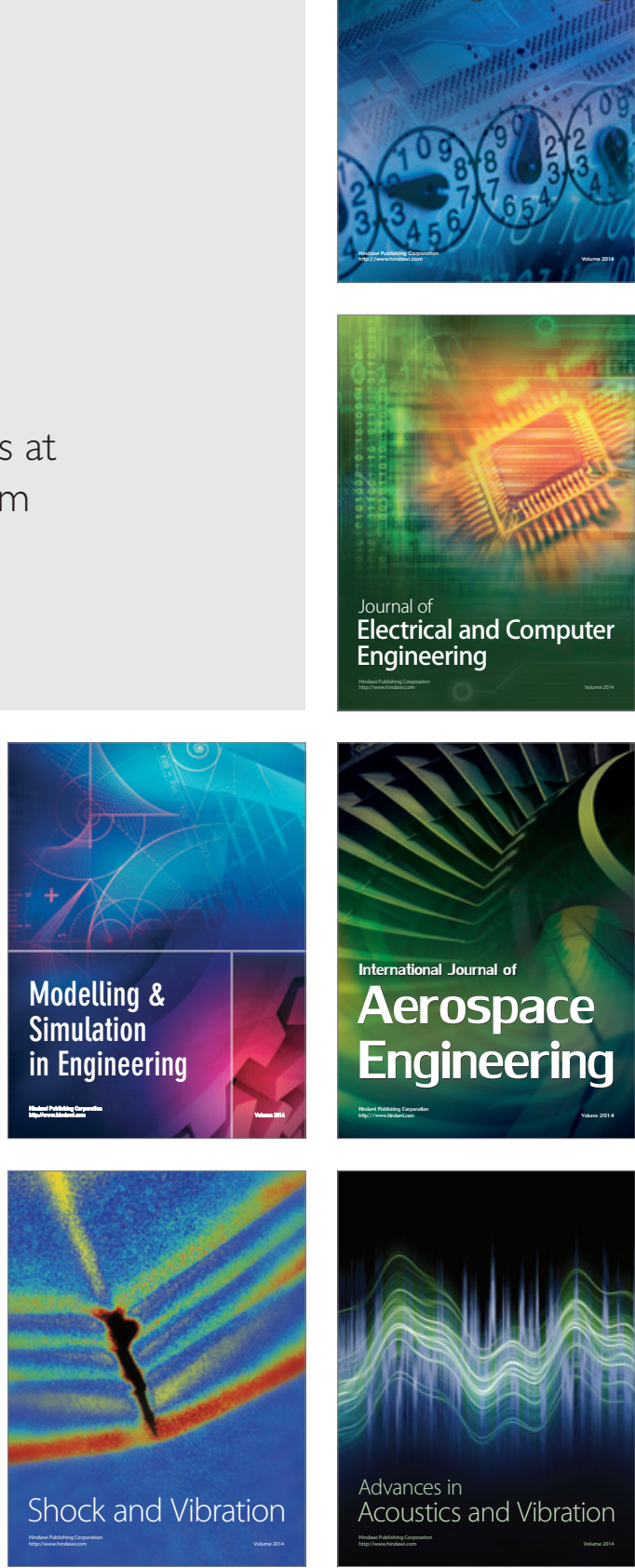